\title{
Revising the Emergency Management Requirements for new generation reactors
}

\author{
Federica C.V. Mancini ${ }^{a}$, Eduardo Gallego ${ }^{\text {b }}$, Marco E. Ricotti ${ }^{\text {c,* }}$ \\ ${ }^{a}$ ENEL, Engineering and Research Division, Nuclear Area, v. Mantova, 24, 00198 Rome, Italy \\ ${ }^{\mathrm{b}}$ Departamento de Ingenieria Nuclear, Universidad Politecnica de Madrid, C. Jose Gutierrez Abascal, 2, Madrid E-28006, Spain \\ ${ }^{\mathrm{c}}$ Politecnico di Milano - Technical University, Department of Energy, Nuclear Engineering Division, via La Masa, 34, 20156 Milan, Italy
}

\section{Keywords:}

EMR

Risk-informed

SMR

GenllI+

\section{A B S T R A C T}

The paper presents the application of a new risk-informed methodology for the identification of the Emergency Management Requirements (EMR) to a Generation II, Large size Reactor and a Generation III+ Small Modular Reactor.

The results obtained in this test case demonstrate that the actual EMR is conservative, as expected, for the GenII reactor, while the new methodology could be applied for the definition of EMRs for the new generation Nuclear Power Plants, with a possible reduction of the emergency area without loss of safety level.

By adopting both probabilistic and deterministic approaches, the study addresses possible accidents and corresponding release scenarios for the two types of reactor, calculates the areas where the accidents have an impact on the population and defines the new EMR considering the health effects on the population,

\section{Introduction}

IAEA Safety Fundamentals (IAEA, 2010) for Nuclear Power Plants (NPPs) and site selection require that adequate protective measures can and will be taken in the event of a radiological emergency. Historically, the Emergency Management Requirements (EMR) were defined according to very conservative parameters independent from the design and the actual safety level of each specific nuclear power plant, e.g. evaluated through Probabilistic Risk Assessment and Deterministic Analysis (IAEA, 1999; NRC, 2003). This conservative approach does not take into account the significant safety improvements in plant operation and design achieved since.

Moreover as a consequence of this conservative approach, the EMR may also pose a significant burden on plant owner, both in the construction and in the operation phase.

During construction, it may be needed to build large infrastructures (e.g. enhanced highways) to comply with the requirement. During operation, it is necessary to maintain an evacuation capability in a relatively wide area around the plant in which, for all practical purposes, any human development is frozen.

\footnotetext{
* Corresponding author. Tel.: +3902 23996325; fax: +3902 23996309.

E-mail address: marco.ricotti@polimi.it (M.E. Ricotti).
}

This could discourage small countries and/or areas with significant growth to invest in the nuclear construction. Finally the fact that the off-site zone around NPP is treated in a special way sends an incorrect message to the public regarding the safety of NPPs and in the unlikely event of an accident could even induce among residents of the affected areas the "paralyzing fatalism" that is recognized to be the largest and long lasting public health problem created by the Chernobyl accident (IAEA, 2005).

The current advanced and safer reactor designs further reduce risk to public, and should therefore offer the possibility to methodologically link the level of safety to the emergency areas and eventually to reduce or to eliminate some of the emergency plan and evacuation requirements. This need was identified by the IAEA INPRO international project (IAEA, 2003) ("The innovative nuclear reactors and fuel cycle shall not need relocation or evacuation measures outside the plant site, apart from those generic emergency measures developed for any industrial facility") as well as by the Generation IV International Forum (GIF) (GIF, 2002). It is deemed possible to reduce emergency-related site requirements for advanced plants, while at the same time providing a protection to the general public equal or better than that provided by the current generation of NPPs and current regulations.

Achieving licensing with this new objective could offer societal and economic benefits to member countries, general public and plant owners/operators, including: 
- enable wider choice of siting locations in countries with relatively high population density;

- increased public acceptance of nuclear power, since they will be treated as any other industrial facility;

- reduced need for infrastructure, thus reducing cost;

- reduced operational costs;

- enabling co-generation, including district heating, desalination and ethanol production, where the plant cannot be located remotely from the intended user;

- enable siting that would reduce transmission costs.

In particular the Small-Medium size Modular Reactors (SMRs) concept (Ingersoll, 2009; Boarin et al., 2012), which is gaining growing interest from several IAEA member countries (IAEA, 2007, 2010b), may effectively and better comply with new safety features required to allow the reduction or even the elimination of the EMR. At the same time SMRs may take advantage from that for their deployment strategy.

In principle EMR criteria could be based on four possible rationales: risk, probability, cost-effectiveness and consequences.

The methodology presented in this paper follows a risk informed approach (ANS, 2011) and links the EMR with the safety level of the nuclear power plant. The methodology is applied to a GenII, large size reactor (LR) and to an enhanced safety GenIII+, SMR.

The purpose of the paper is a preliminary demonstration of the potentialities of the risk-informed methodology in evaluating the EMRs, taking into account the safety improvements obtained in the GenIII+, new reactor designs. The analysis presented in this paper reflects the limited availability of suitable data in the open literature as well as the complexity of a thorough evaluation. Due to the preliminary and demonstrative goal of the analysis, the evaluation does not cover the impact of external events and does not consider the possible post-Fukushima scenarios. The data used for the analysis are the results of level 2-PSAs based only on at-power internal events; for the GenIII+ reactor also the Fuel Handling Accident has been considered.

To obtain a complete analysis, a supplementary evaluation of the impact of the site-dependent external hazards should be performed.

Nevertheless, the above-mentioned limitations do not impair the validity of the risk-informed approach and the test.

The EMR areas estimated with the methodology for both the types of reactor are shown and compared.

\section{Current EMR approach and previous studies}

The birth of the EMR concept, originally called Emergency Planning Zone (EPZ), was introduced after the construction of the early nuclear power plants. The National Regulators established the EMR following the international advise based on the Design Basis Accidents (DBA), the current EMR are reported in Table 1. Besides, the extension of the EMR for the protection against beyond design basis accidents (BDBA) is site dependent and evaluated according with the NPP safety features. In general, countermeasures for the BDBA can be decided in detail after the accident is occurred, because more time would be available for the emergency response beyond the established distances. After the Fukushima accident, a revision of the actual requirements has been implemented in some countries (NRC, 2011). The increased Emergency Preparedness now has to include emergency plans and sustained assistance for prolonged station blackout and multiunit events. To ensure protection, the station blackout mitigation capability has to be enhanced considering also the design basis and beyond design basis external events.
Table 1

Current EMR in some countries.

\begin{tabular}{|c|c|c|c|c|}
\hline \multirow[t]{2}{*}{ USA } & 10 miles & $\begin{array}{l}\text { Plume } \\
\text { exposure } \\
\text { pathway }\end{array}$ & $\begin{array}{l}\text { Exclusion } \\
\text { area }\end{array}$ & $\begin{array}{l}\text { Total radiation dose to whole } \\
\text { body in } 2 \mathrm{~h}>25 \mathrm{rem} \\
\text { Total radiation dose to the } \\
\text { thyroid from iodine exposure } \\
\text { in } 2 \mathrm{~h}>300 \text { rem }\end{array}$ \\
\hline & 50 miles & $\begin{array}{l}\text { Ingestion } \\
\text { exposure } \\
\text { pathway }\end{array}$ & $\begin{array}{l}\text { Low } \\
\text { population } \\
\text { zone }\end{array}$ & $\begin{array}{l}\text { Total radiation dose to whole } \\
\text { body during the entire period of } \\
\text { passage }>25 \text { rem } \\
\text { Total radiation dose to the } \\
\text { thyroid from iodine exposure } \\
\text { during the entire period of } \\
\text { passage }>300 \text { rem }\end{array}$ \\
\hline \multirow[t]{2}{*}{ France } & $\begin{array}{l}5 \mathrm{~km} \\
10 \mathrm{~km}\end{array}$ & & $\begin{array}{l}\text { Evacuation } \\
\text { Sheltering } \\
\text { Stable iodin }\end{array}$ & $\begin{array}{l}\text { re-planned } \\
\text { e-planned } \\
\text { tablets distributed }\end{array}$ \\
\hline & $>10 \mathrm{~km}$ & & \multicolumn{2}{|c|}{ Possible extension of protective actions } \\
\hline \multirow[t]{2}{*}{ Spain } & $10 \mathrm{~km}$ & & \multicolumn{2}{|c|}{$\begin{array}{l}\text { Sheltering, evacuation and stable iodine } \\
\text { intake in the preference sector }\end{array}$} \\
\hline & $30 \mathrm{~km}$ & & \multicolumn{2}{|c|}{ Food restrictions } \\
\hline Japan & $8-10 \mathrm{~km}$ & & \multicolumn{2}{|c|}{$\begin{array}{l}\text { Lower limit of radiation exposure } \\
\text { between } D<10 \mathrm{mSv} \text { whole body }\end{array}$} \\
\hline
\end{tabular}

\subsection{Past studies and previous attempts}

The analysis of past experiences (Thompson, 1997; EPRI, 1999; NEI, 2002; EUR, 2002; Lee et al., 2004) suggests the adoption of a mixed deterministic and probabilistic approach which still involves a relevant modification in the fundamental EMR defining criteria as currently conceived (i.e., from consequences, as it is currently, to risk).

The proposed methodology is based on accepted concepts such as PRA techniques and deterministic dose evaluation as used in current practice; it suggests a more complete definition of the current and accepted criteria for the EMR by focussing on the frequency of exceeding a given dose at a given distance. The EMR can be redefined while still maintaining the same dose (explicitly defined in the current Protective Action Guides-PAG) and the same frequency (implicitly defined by the choice of a fixed distance) defined by the regulatory body.

The proposed methodology addresses the two conceptual weaknesses highlighted for previous efforts in the redefinition of the EMR defining criteria:

- in the deterministic part of the methodology all the foreseen sequences including severe accidents, are evaluated. Severe accidents are limiting scenarios but cannot be removed from the analysis without infirming the completeness of the methodology. Previous attempts in the EMR redefinition were rejected because lacking a satisfactory account of severe accidents;

- the probabilistic part is shifted from establishing a cut-off frequency. This screening criterion of accident sequences evaluates the frequency to overcome the dose limit at a certain distance. By means of the data provided by PRAs, such a distance can be evaluated rather than pre-set. Arbitrary selection of the cut-off frequency value represented the major objection against the probabilistic approach to EMR redefinition.

The methodology presented here will combine probabilistic, deterministic, and risk management methods that would support licensing with reduced emergency planning requirements. It is articulated over the following steps:

- Review the licensing regulations which specify the emergency response planning for the current Light Water Reactor (LWR) plants. 
- Based on the lessons learned by previous attempts at EMR redefinition, identify changes in the licensing approach and devise technical criteria which would be necessary if the emergency planning is to be eliminated or reduced

- Develop an integrated methodology based on combination of the deterministic, probabilistic and risk management approach, which would enable consistent evaluation of advanced reactors, giving credit to their enhanced safety features.

\section{A risk-informed approach to the EMR area definition}

The proposed methodology is aimed at providing a riskinformed definition of the EMR, once the basic acceptance criteria in terms of limiting dose and limiting frequency have been provided (i.e., agreed upon with regulatory bodies).

The integrated deterministic and probabilistic procedure can be summarized in five steps described in the following sections.

The probabilistic starting point of this methodology (i.e., step 1) essentially covers the choice of the set of release scenarios to be addressed by a deterministic evaluation of the consequences.

In order to obtain this outcome, the entire spectrum of accident sequences defined through the PRA of the plant must be reviewed and re-categorized, in terms of frequency of occurrence and expected releases, resulting in families of dose-distance profiles. No additional cut-off frequencies are introduced, but the same truncation level applied and accepted for the PRA development must be maintained and should reasonably guarantee to cover unlikely sequences.

A set of accident release scenarios $\left(A_{i}\right)$ with their corresponding frequency of occurrence $f_{i}$ is therefore the outcome of this first step of the methodology. In Fig, 1 a schematic representation of the results of this step is presented, where five release scenarios are obtained after the re-categorization.

Once the set of release scenarios has been identified, the second step is a deterministic evaluation of the consequences. Appropriate assumptions must be made in order to outline the scenario phenomenology; such assumptions should be based in a wider extent on best estimate, realistic models rather than on large and overconservative safety coefficients. Using appropriate codes, the dose absorbed by a hypothetical individual located at various distances from the reactor, during the days (especially the first hours) after the onset of the accident is calculated. This calculation should be performed considering a complete set of meteorological conditions.

The final outcome of this step is a set of curves of dose equivalent $(D)$ vs. distance $(x)$, one curve for each accident release scenario $\left(A_{i}, f_{i}\right)$. Fig. 2 represents a conceptual example of the results of this second step applied to the five release scenarios hypothetically identified in Fig. 1.

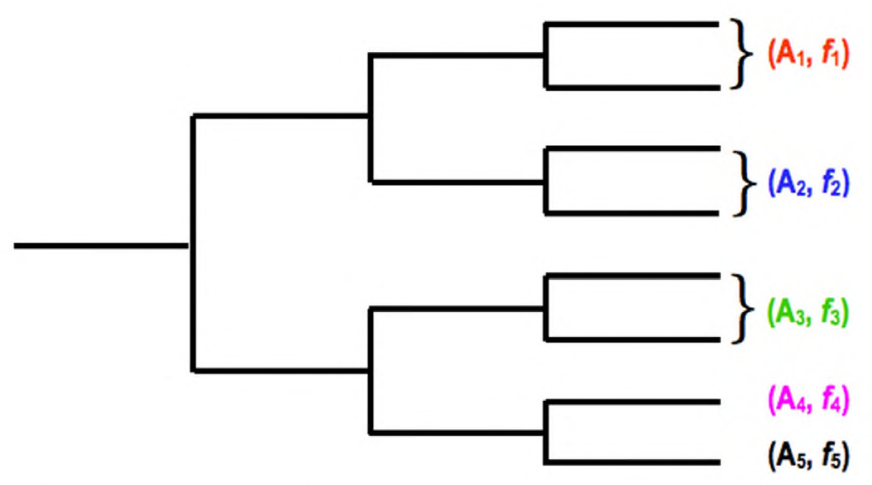

Fig. 1. Accidents re-categorization (conceptual): $A=$ accident scenario, $f=$ occurrence frequency.

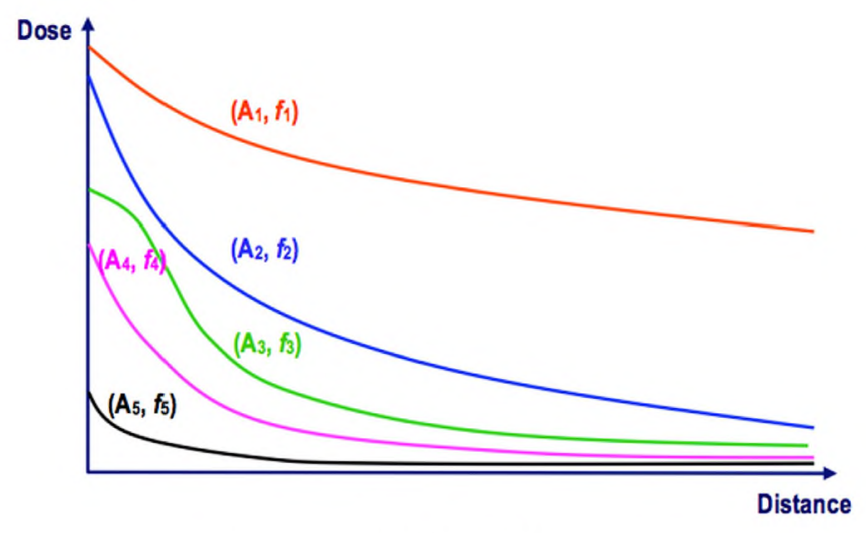

Fig. 2. Dose vs. distance (conceptual).

To be able to combine the probabilistic and the deterministic contributions, a limiting dose $D^{*}$ and a limiting frequency $f^{*}$ are identified in steps 3 and 4 , respectively. These are two steps that require regulatory and licensing considerations since the limiting values should ideally be suggested by and/or agreed with a regulatory body.

Even though these two steps will require further investigation, as far as the limiting dose $D^{*}$ is concerned, the current consequence-oriented approach for the selection of the EMR defining criteria is felt to be able to concur in an easy identification of a value of general consensus, e.g. the PAG suggested by the US EPA (EPA, 1975), typically in the range of 1 rem or $100 \mathrm{mSv}$.

The identification of a limiting frequency, $f^{*}$, is on the other hand more controversial. However a value of $10^{-7}$ recurrently appears in various documents (NRC, 1981, 1990, 1991), hence it can be reasonably used as the $f^{*}$ value for a first approximation of the methodology.

The aim of the direct application of this methodology is the evaluation of the frequency of exceeding a limiting dose, rather than the frequency of occurrence of some accidents.

The fifth and final step is the combination of the probabilistic and deterministic contributions previously mentioned to determine the size of the EMR. The methodology as follows: each of the curves of dose vs. distance (evaluated for each $A_{i}$ release scenario) is solved for $D^{*}$ in Fig. 3 .

That is, from the dose vs. distance curves the distance $x_{i}$ for which the calculated dose is equal to $D^{*}$ is easily identified. This is repeated for each scenario until a family of values of $x_{i}$ is generated.

By the definition of $x_{i}$ (distance at which the limit dose occurs) and foregoing the uncertainties associated with the analysis, for each scenario $A_{i}$ there would be a probability 1.0 of exceeding $D^{*}$ at

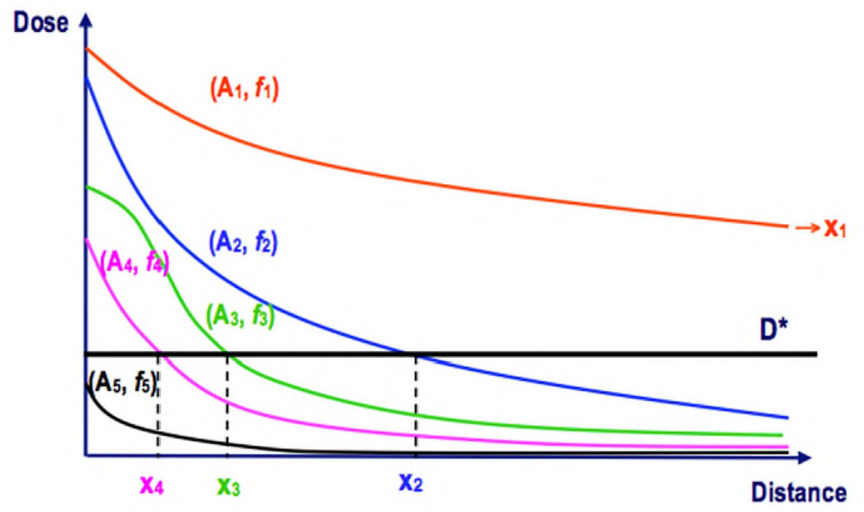

Fig. 3. Limiting dose solving. 
a distance smaller than $x_{i}$ and a probability 0.0 of exceeding $D^{*}$ at a distance larger than $x_{i}$. These probabilities should then be multiplied by the PRA calculated frequencies of the occurrence of each accident so that the frequency of exceeding the $D^{*}$ at a distance smaller than $x_{i}$ would be, for each scenario, $f_{i}$.

Note that it can be reasonably expected that the larger $x_{i}$ will be associated with the more severe accidents, which should in turn have the lower frequencies. The $x_{i}$ are then ordered by decreasing values so that the frequencies of exceeding the dose limit as a function of distance can be calculated by simply considering, for each distance $x_{i}$, the contributions of all scenarios $A_{i}$ that at the selected distance induce a released dose higher than the limiting dose. The combination is therefore as follows: where $f_{D^{+}}(x)$ is the "Frequency of exceeding dose limit $D^{*}$ at the distance $x^{\prime}$.

The frequency of a release dose higher than the limiting dose is defined by

$f_{D^{*}}\left(x_{i}\right)=\sum_{i, i: D\left(x_{i}\right)>D^{*}}^{n} f_{i}$

Thus a histogram of $f_{D^{*}}$ vs. distance can be completed. The last remaining input to the methodology, and a critical one, is the previously identified $f^{*}$ of exceeding the $D^{*}$ that should be used to define the associated distance determining the EMR (Fig. 4).

The EMR distance will in fact be defined as the distance with a frequency equal to or greater than the given limiting frequency (e.g. $x_{3}$ in Fig. 4 , being $f_{1}+f_{2}+f_{3}$ the lowest summation of frequencies which is greater than the given $f^{*}$ ).

\section{Methodology application and results}

The described methodology is tested in its principles and procedure through its application to a GenII LR and a GenIII+ SMR. The starting point of the analysis is a level 2 PSA with a detailed study of all the accident sequences with the corresponding source terms. As far as the application to a GenII reactor is concerned, the results of the new methodology are expected to be consistent with the current regulation, given the suitable level of conservativeness usually adopted in nuclear rules and laws.

The further application of the same risk informed methodology to a GenIII+ reactor, is a test bed for an adequate evaluation of its enhanced safety. New generation reactors usually claim such new, higher safety levels: the application aims at quantifying the impact of the new safety features on the EMR item.

\subsection{GenII and GenIII+ reactors short description}

The GenII reactor is a currently operating PWR, Pressurized Water Reactor, with standard safety features. It is a two loop reactor

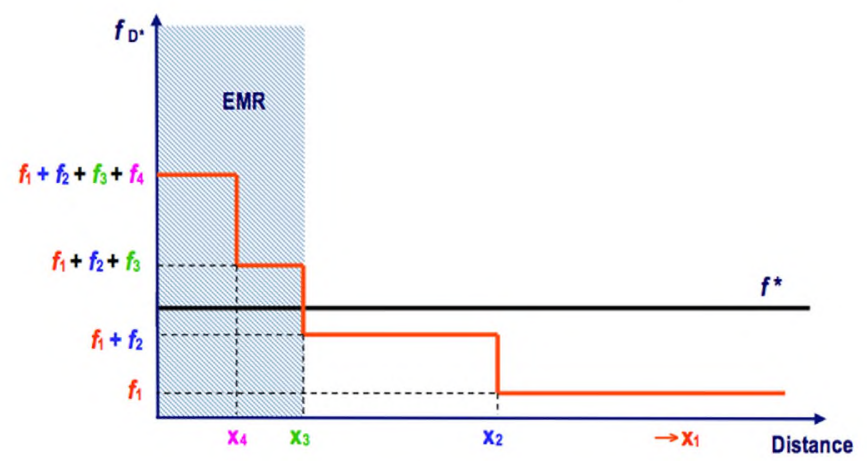

Fig. 4. EMR area definition. with thermal power $2950 \mathrm{MW}$ and electrical power $1060 \mathrm{MW}$, belonging to ' 80 s' technology. The reactor has a double possibility of refrigeration: from a river and with cooling towers. The safety systems are of active type.

The GenIII+ concept is the IRIS (International Reactor Innovative and Secure) reactor (Petrovic et al., 2012), considered as a representative innovative light-water SMR. IRIS design is fundamentally based on an integral PWR, hence with its primary components (core, steam generators, main circulation pumps, control rod drive mechanism, pressurizer) located into the reactor pressure vessel. The Safety-By-Design strategy adopted during the concept development phase and the corresponding risk-informed approach (Fig. 5) in the design phase (i.e., a continuous iteration of probabilistic and deterministic analysis and design update), led to a $10^{-8}$ event/reactor year Core Damage Frequency evaluation, mainly based on the implementation of passive safety systems, a steel and spherical, pressure suppression containment with large pools and seismically isolated containment and auxiliary buildings.

\subsection{Dose evaluation process}

The risk-informed methodology for the EMR Area definition has been applied according to the procedural scheme depicted in Fig. 6 . Suitable plant data for the GenII and GenIII+ reactors, to be analysed, are needed to perform the Level 1 and Level 2 PRA. The main results of the probabilistic assessment, i.e., the accident sequences leading to core damage and to early release and the corresponding clustered release scenarios together with their occurrence frequencies, were used to feed MAAP (MAAP, 1994) and RADTRAD (Humphreys et al., 1998) codes, used for the GenII, LR and the GenIII+, SMR source term evaluation, respectively. The codes provide the input data for the release scenarios, simulated by RODOS (Real time On-line Decision Support) code (RODOS, 2008; Ehrhardt et al., 1993; Ehrhardt, 1997; Rojas-Palma et al., 2003) to evaluate the dose vs. distance curves. The system provides consistent information for the off-site emergency management in Europe. RODOS, developed within the EU Framework Program and involving several organizations and countries within the European Union and Russia, is based on databases that collect the inventory of all nuclear power plants in Europe and Russia, the source term for standard accidents and information on geography, population density and population activities for all the sites.

RODOS performs detailed diffusion calculation through real time meteorological data feed from the national meteorological institute and a 3D DMI-HIRLAM (HIgh Resolution Limited Area) model dedicated to weather previsions.

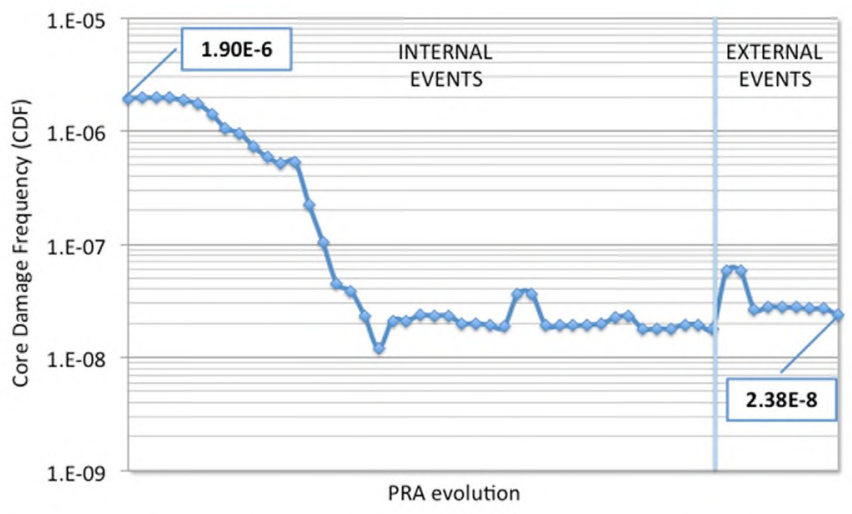

Fig. 5. CDF reduction for the SMR (IRIS) reactor in the design phase (risk-informed process). 


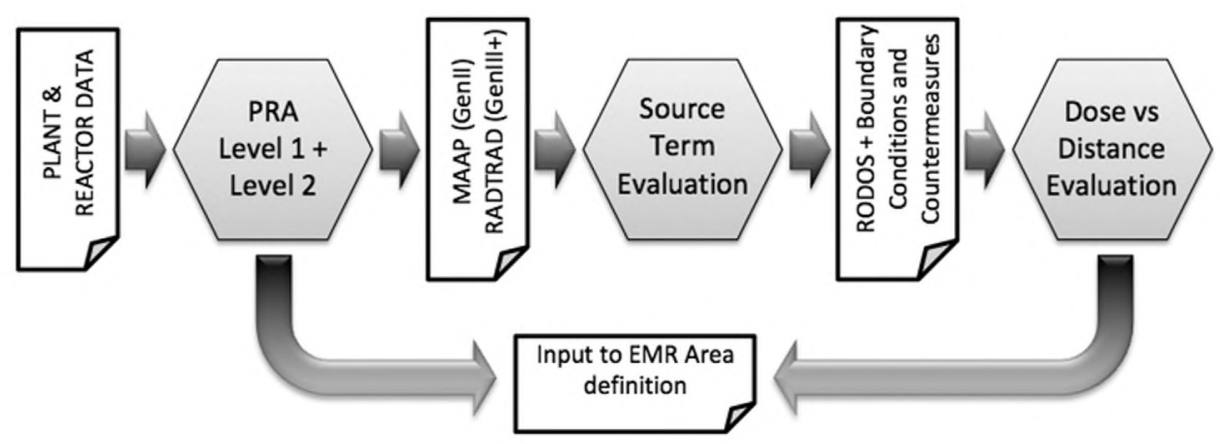

Fig. 6. Procedural scheme of EMR methodology.

Among the several RODOS outputs, those used in this work are the evaluated potential doses, the long term doses, the activity concentrations in air, in foodstuff and in feedstuff and the corresponding ground contamination and dose rates.

The EMERSIM model (Päsler-Sauer, 2007) included in the code is actually able to apply and evaluate countermeasures with a quantification of their benefits and disadvantages. The results are the area involved by the countermeasures and the number of persons implicated in the protective action.

An evaluation and ranking of alternative countermeasures strategies is also possible by balancing the respective benefits and disadvantages, which take into account societal preferences.

\subsection{Release scenarios}

The first step of the methodology consists in the identification of the release scenarios to be analyzed. For the GenII reactor, all the severe accidents detailed in the level 2 PSA are included in the analysis. The PSA describes the characteristics of the accidents, such as the delay between the reactor SCRAM and the beginning of the release, along with the expected frequencies. The releases' durations, a further input required by RODOS, are normally defined through the expert opinion.

The set of release scenarios and corresponding features for the GenII, LR is summarized in Table 2.
For the GenIII+ SMR, the release scenarios are obtained from a suitable group categorization of the accident sequences from the PRA. The focus is upon the presence of common release pathways for the off-site dose evaluation rather then on common mitigation strategies and/or plant responses.

The re-grouping of the PRA sequences is performed in a double step fashion (Fig. 7). In the initial step a set of release sequences is defined starting from the accident sequences identified in the PRA; this first step takes into consideration deterministic aspects as well as probabilistic aspects. The PRA sequences are then quantified and the resulting frequencies combined in order to assign a frequency to each of the release sequences. In the second grouping step, conservative assumptions and simplifications are formulated to reduce the number of release sequences to a reasonably manageable number which must consider both high unlikely releases and low more-probable releases as well.

The release categories addressed during the preliminary IRIS source term and dose evaluation analysis are considered as starting points for the definition of a first set of release sequences. The entire re-categorization process cannot be reported herein due to the proprietary nature of some of the details; basically, the release categories have been matched with the 418 accident sequences (that are grouped in 5 Plant Damage States - PDS - categories) defined during the preliminary IRIS PRA. The grouping has been mainly based on the foreseen pathways offered to the radioactivity

Table 2

GenII, LR release scenarios.

\begin{tabular}{|c|c|c|c|c|}
\hline Release category & Release scenarios description & $\begin{array}{l}\text { Overall frequency } \\
\text { [event/ry] }\end{array}$ & $\begin{array}{l}\text { Delay from } \\
\text { SCRAM [h] }\end{array}$ & $\begin{array}{l}\text { Release's } \\
\text { duration }{ }^{\mathrm{a}}[\mathrm{h}]\end{array}$ \\
\hline R1 & $\begin{array}{l}\text { Containment failure previous or } \\
\text { upon vessel failure, safety injection and recirculation } \\
\text { sprinkler systems operating }\end{array}$ & $7.64 \times 10^{-9}$ & 8.37 & 1 \\
\hline $\mathrm{R} 2$ & $\begin{array}{l}\text { Like R1, but safety injection and recirculation } \\
\text { sprinkler systems not operable }\end{array}$ & $8.3 \times 10^{-10}$ & 2.9 & 2.5 \\
\hline R3 & $\begin{array}{l}\text { Late containment failure before } 48 \mathrm{~h} \text { after core meltdown, } \\
\text { sprinkler system operating }\end{array}$ & $2.73 \times 10^{-6}$ & 45.92 & 1 \\
\hline R4 & $\begin{array}{l}\text { Late containment failure } 48 \mathrm{~h} \text { before core damage, } \\
\text { sprinkler system operating after AC recovered }\end{array}$ & $2.74 \times 10^{-8}$ & 35.75 & 3.5 \\
\hline R5 & Like R4, but sprinkler system not operable & $2.03 \times 10^{-7}$ & 36.35 & 1 \\
\hline R6 & $\begin{array}{l}\text { Failure of containment between } 48 \mathrm{~h} \text { and } 120 \mathrm{~h} \\
\text { after core damage, spray operable in recirculation mode }\end{array}$ & $1.44 \times 10^{-5}$ & 91.26 & 5 \\
\hline R7 & $\begin{array}{l}\text { Failure of containment between } 48 \mathrm{~h} \text { and } 120 \mathrm{~h} \\
\text { after core damage, sprinkler system not operable }\end{array}$ & $2.71 \times 10^{-6}$ & 80.26 & 5 \\
\hline R8 & Design Basis Accident, containment remains intact & $9.73 \times 10^{-6}$ & 3 & 12 or more \\
\hline R9 & Penetration of concrete slab & $1.72 \times 10^{-5}$ & 91.98 & 12 or more \\
\hline $\mathrm{R} 10$ & SG tube rupture, initiating event or induced by temperature & $3.94 \times 10^{-6}$ & 17.8 & 2 \\
\hline R11 & Containment isolation failure & $1.06 \times 10^{-6}$ & 2.3 & 2 \\
\hline R12 & $\begin{array}{l}\text { Containment bypass and transition to secondary } \\
\text { through SG tubes or CVCS }\end{array}$ & $5 \times 10^{-6}$ & 13.27 & 2 \\
\hline
\end{tabular}

a Data from expert elicitation. 


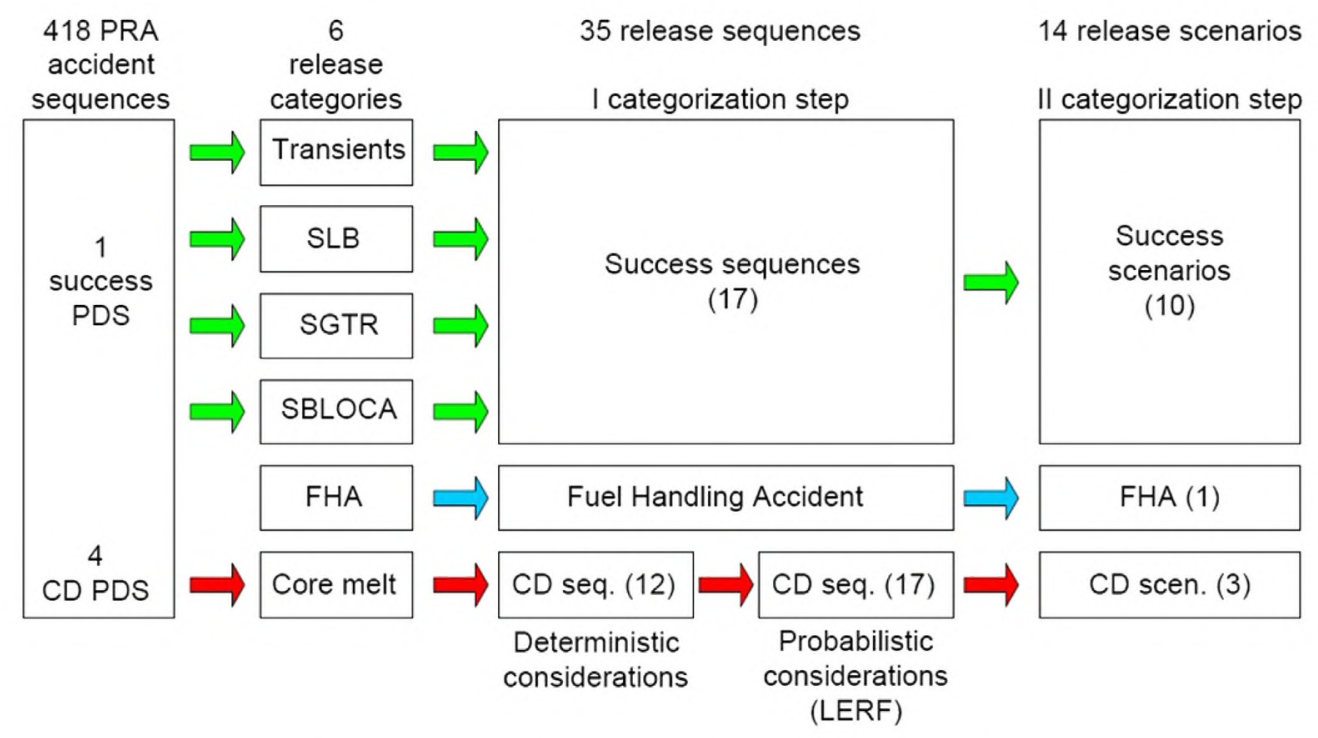

Fig. 7. SMR (IRIS) accident sequences re-categorization summary schematics.

release following both the onsite of the accident and the actuation of the main mitigation systems; therefore, the differentiation introduced during the PRA study as a result of considerations of single systems success criteria have been removed, also lumping together accident sequences originating from different IEs.

Success sequences are those that present the higher variability in the dose release, due to the different kind of IE originating the sequence (e.g. a successfully mitigated SGTR could potentially induce an initial higher release outside containment than a successfully mitigated LOCA); for this reason they have been modelled in the more detailed way and originate the most numerous release categories. As far as CD scenarios are concerned, 4 release scenarios have been identified.

The following step was the computation of their related value of frequency. In case of the release scenarios without $C D$, the overall frequencies are obtained by simple addition of the frequencies of all the involved accident sequences grouped in the scenario under evaluation. In case of $\mathrm{CD}$ scenarios some additional considerations from the preliminary LERF model developed for IRIS have been credited.

The Fuel Handling Accident (R14) scenario is obviously treated in a different way, since this is not an at-power accident sequence and it is therefore not covered by the Level-1 PRA so far developed for IRIS. A Fuel Handling Accident is an event where a fuel assembly is mechanically damaged and gap activity is released. This accident is not normally accounted for as a significant contributor to a plant's total risk profile in modern Low Power Shut Down (LPSD) PRAs.

Values associated with an asterisk $\left(^{*}\right)$ are not available in the PRA neither in the accident description so they are suggested by experts. The results are reported in Table 3.

\subsection{Source term}

As far as the source terms are concerned, for the three loops PWR the PSA gives the related values as a percentage of the total inventory. These values are the result of deterministic calculations performed with MAAP code and validated by further analyses with MELCOR code (Gauntt et al., 2005). To perform this latter calculation, the code regroups all the isotopes of the inventory into different families.

Each release scenario is evaluated via RODOS code runs. The code accepts directly as source term input the percentages by the PSA, since its database includes the total inventories of all the European NPPs, calculated in core equilibrium conditions, RODOS takes into account the main six families of inventory isotopes (Xe, I, $\mathrm{Cs}, \mathrm{Te}, \mathrm{Ba}, \mathrm{Ru}-\mathrm{La}-\mathrm{Ce}$ ).

Table 3

GenIII+, SMR (IRIS) release scenarios.

\begin{tabular}{|c|c|c|c|c|c|}
\hline Release category & Release scenarios description & $\begin{array}{l}\text { Involved PRA } \\
\text { sequences }\end{array}$ & $\begin{array}{l}\text { Overall frequency } \\
\text { [event/ry] }\end{array}$ & $\begin{array}{l}\text { Delay from } \\
\text { SCRAM [h] }\end{array}$ & $\begin{array}{l}\text { Release's } \\
\text { duration [h] }\end{array}$ \\
\hline R1 & Transients successfully mitigated via MFWS & 15 & $1.14 \times 10^{-0}$ & $4^{\mathrm{a}}$ & 30 \\
\hline $\mathrm{R} 2$ & ATWS successfully mitigated via OTCC & 108 & $8.9 \times 10^{-7}$ & $0^{\mathrm{a}}$ & $1^{\mathrm{a}}$ \\
\hline R3 & SGTR successfully mitigated via MFWS & 2 & $1.77 \times 10^{-4}$ & $0^{\mathrm{a}}$ & 30 \\
\hline R4 & SGTR successfully mitigated via EHRS & 2 & $1.1 \times 10^{-5}$ & $0^{\mathrm{a}}$ & 84.33 \\
\hline R5 & SGTR successfully mitigated via OTCC & 2 & $1.68 \times 10^{-11}$ & $0^{\mathrm{a}}$ & $84.33^{\mathrm{a}}$ \\
\hline R6 & Not isolated SGTR successfully mitigated via EHRS & 1 & $1 \times 10^{-8}$ & $0^{\mathrm{a}}$ & 84.33 \\
\hline R7 & Not isolated SGTR successfully mitigated via OTCC & 3 & $2.41 \times 10^{-13}$ & $0^{\mathrm{a}}$ & $84.33^{\mathrm{a}}$ \\
\hline R8 & Steam line break successfully mitigated via EHRS & 2 & $9.68 \times 10^{-4}$ & 0 & 24 \\
\hline R9 & Steam line break successfully mitigated via OTCC & 12 & $2.9 \times 10^{-8}$ & $0^{\mathrm{a}}$ & $24^{\mathrm{a}}$ \\
\hline R10 & Small break LOCA successfully mitigated & 25 & $1.02 \times 10^{-3}$ & $0^{\mathrm{a}}$ & $3^{a}$ \\
\hline R11 & Early core melt with heat removal capability & 211 & $2 \times 10^{-8}$ & 6.5 & $5^{\mathrm{a}}$ \\
\hline R12 & Late core melt with heat removal capability & 211 & $4.47 \times 10^{-10}$ & 7.5 & $5^{\mathrm{a}}$ \\
\hline R13 & Core melt with containment failure & 211 & $7.05 \times 10^{-9}$ & - & - \\
\hline R14 & Fuel handling accidents & $\mathrm{N} / \mathrm{A}$ & $1 \times 10^{-4}$ & 96 & 2 \\
\hline
\end{tabular}

\footnotetext{
${ }^{a}$ Data from expert elicitation.
} 
Since the IRIS total inventory is not available in RODOS database, the source term is given directly as an input, in terms of activity (in $\mathrm{Bq}$ ) for each isotope, up to 24 different isotopes (the maximum number of input isotopes in RODOS). These values are obtained from deterministic calculations of each release scenario for IRIS, performed by means of RADTRAD code runs. RADTRAD is a simplified code with respect to the modelling in RODOS, but it is able to perform both internal and external NPP release analysis. The source terms have been extracted from the RADTRAD outputs, considering all the release pathways from the core to the NSSS boundary.

RADTRAD requires the definition of pathways among the compartments, for the IRIS model it can be envisioned 13 pathways that are summarized in Fig. 8.

The reactor inventory is composed by hundreds of elements, in Table 4 there is an excerpt of the total inventory. The PWR inventory comes from the RODOS database, IRIS inventory is calculated with a $2 \%$ uncertainty. There are indicated for each family of MELCOR evaluation one nuclide in becquerel.

The source term can be given like a percentage of the total inventory, in Table 5 and in Table 6 are indicated percentages for the evaluated isotopes. For the GenII, LR these values come from the PSA, for the GenIII+, SMR are calculated from the known release and the total inventory.

\subsection{Limiting frequency and dose limits criteria}

The following steps of the procedure require identifying a limiting frequency and doses.

The identification of the limiting frequency $f^{*}$ can be a controversial matter; reliance is given on literature studies that identifies $1 \times 10^{-7}$ event/r y as a value of general consensus for a meaningful decision-making process.

On the dose limit side, the International Commission on Radiological Protection (ICRP, 1999) defines the dose limit with a reference level, expressed in terms of residual dose that has to be set, typically between $20 \mathrm{mSv}$ and $100 \mathrm{mSv}$ effective dose, which includes dose contributions from all exposure pathways. The
Table 4

GenII and GenIII+ reactors inventory excerpt (in $\mathrm{Bq}$ ).

\begin{tabular}{lllllll}
\hline & Kr-85 & l-131 & Cs-137 & Te-132 & Sr-90 & Nb-95 \\
\hline GenII (LR) & $2.86 \mathrm{E} 16$ & $2.42 \mathrm{E} 18$ & $3.10 \mathrm{E} 17$ & $3.43 \mathrm{E} 18$ & $2.25 \mathrm{E} 17$ & $4.25 \mathrm{E} 18$ \\
GenIII+(SMR) & $1.90 \mathrm{E} 16$ & $1.02 \mathrm{E} 18$ & $2.33 \mathrm{E} 17$ & $1.50 \mathrm{E} 18$ & $\mathbf{1 . 7 6 E} 17$ & $1.78 \mathrm{E} 18$ \\
\hline
\end{tabular}

Table 5

GenII, LR source term excerpt (inventory released, in \%).

\begin{tabular}{lllllll}
\hline Release category & Kr-85 & I-131 & Cs-137 & Te-132 & Sr-90 & Nb-95 \\
\hline R1 & 99.3 & 6.94 & 6.94 & 4.39 & 1.61 & 0.11 \\
R2 & 100 & 28.3 & 28.3 & 12.5 & 4.69 & 0.3 \\
.R3 & 99.2 & 3.84 & 3.84 & 1.65 & 0.24 & $2.99 \mathrm{E}-4$ \\
R4 & 99.8 & 2.26 & 2.26 & 1.02 & 0.18 & $9.83 \mathrm{E}-4$ \\
R5 & 99.3 & 4.64 & 4.64 & 2.06 & 0.33 & $1.91 \mathrm{E}-3$ \\
R6 & 99 & 6.29 & 6.29 & 2.68 & 0.37 & $1.04 \mathrm{E}-4$ \\
R7 & 99.3 & 4.6 & 4.6 & 2.01 & 0.31 & $6.02 \mathrm{E}-4$ \\
R8 & 1.46 & $3.38 \mathrm{E}-3$ & $3.38 \mathrm{E}-3$ & $1.19 \mathrm{E}-3$ & $4.08 \mathrm{E}-4$ & $2.55 \mathrm{E}-5$ \\
R9 & 3.1 & $3.93 \mathrm{E}-3$ & $3.93 \mathrm{E}-3$ & $4.18 \mathrm{E}-3$ & $1.59 \mathrm{E}-3$ & $1.07 \mathrm{E}-4$ \\
R10 & 83.1 & 19 & 19 & 6.74 & 2.72 & 0.18 \\
R11 & 92.2 & 6.81 & 6.81 & 5 & 1.87 & 0.13 \\
R12 & 99.5 & 8.34 & 8.34 & 6.3 & 2.39 & 0.16 \\
\hline
\end{tabular}

protection strategy has to be optimized to reduce residual doses below the reference level.

The first step of the analyses is the calculation of the area affected by the accident and by countermeasures. The area involved in the accident is where the effective dose is greater than the limiting dose $D^{*}=100 \mathrm{mSv}$. This limiting dose of $100 \mathrm{mSv}$ is an effective dose calculated in 30 days for a population living on open air and eating all the products of the contaminated area. These hypotheses are very conservative because the most relevant contribution to the dose is the ingestion dose.

While these dose limits were preliminarily applied to both the GenII and GenIII+ reactors, a further analysis has been performed for the GenIII + SMR only, with a limiting dose reduced to $10 \mathrm{mSv}$, calculated in the same conservative conditions. A dose lower than this $10 \mathrm{mSv}$ warrants that the countermeasures are never necessary.

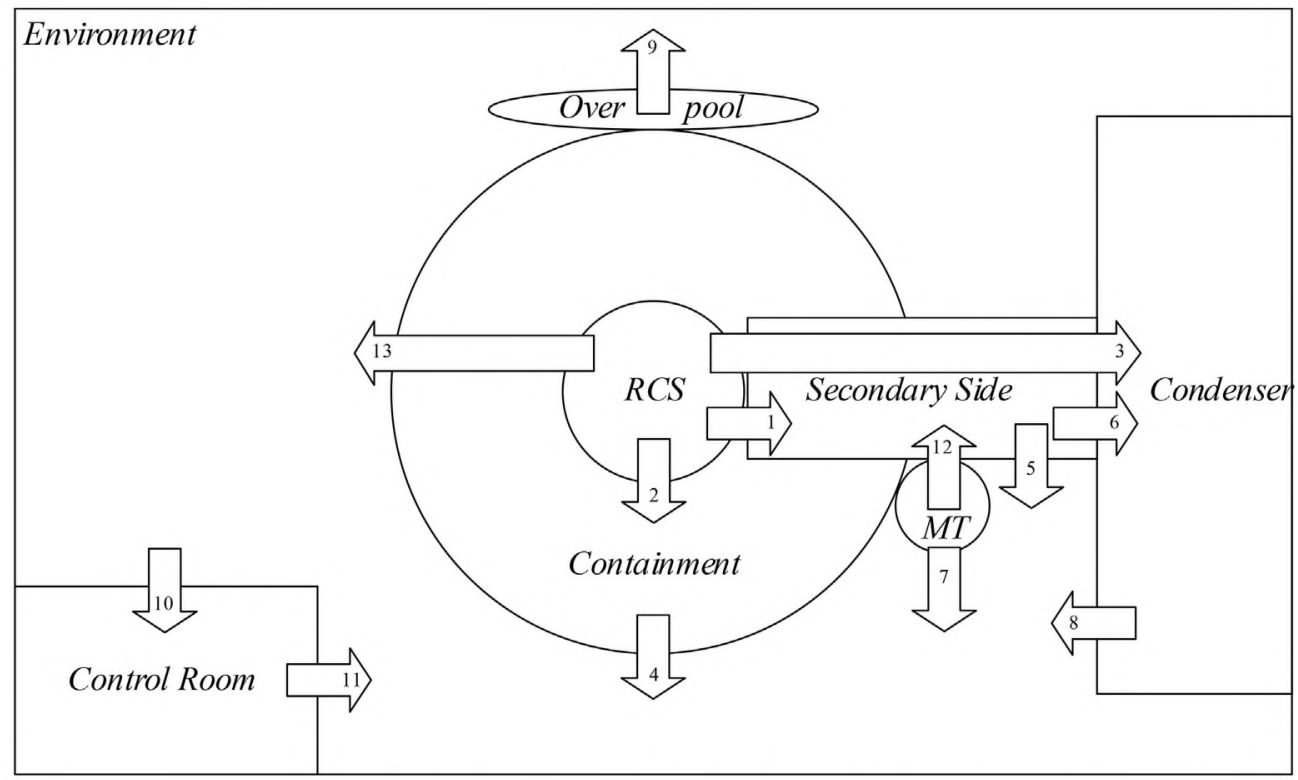

Fig. 8. GenIII+, SMR (IRIS) compartment and pathways used for dose analysis. 
Table 6

GenIII+, SMR source term excerpt (inventory released, in \%).

\begin{tabular}{lllllll}
\hline Release category & Kr-85 & I-131 & Cs-137 & Te-132 & Sr-90 & Nb-95 \\
\hline R1 & $2.9 \mathrm{E}-4$ & $2.9 \mathrm{E}-5$ & $9.3 \mathrm{E}-7$ & $\mathrm{NA}$ & $\mathrm{NA}$ & NA \\
R2 & $7.0 \mathrm{E}-3$ & $4.5 \mathrm{E}-5$ & $3.8 \mathrm{E}-6$ & $\mathrm{NA}$ & NA & NA \\
R3 & $1.1 \mathrm{E}-2$ & $1.3 \mathrm{E}-3$ & NA & NA & NA & NA \\
R4 & $3.1 \mathrm{E}-3$ & $1.2 \mathrm{E}-4$ & NA & NA & NA & NA \\
R5 & $3.8 \mathrm{E}-3$ & $1.5 \mathrm{E}-4$ & NA & NA & NA & NA \\
R6 & $5.4 \mathrm{E}-3$ & $1.5 \mathrm{E}-4$ & NA & NA & NA & NA \\
R8 & $6.2 \mathrm{E}-5$ & $4.8 \mathrm{E}-6$ & NA & NA & NA & NA \\
R9 & $6.7 \mathrm{E}-4$ & $2.9 \mathrm{E}-5$ & NA & NA & NA & NA \\
R10 & $6.9 \mathrm{E}-4$ & $1.2 \mathrm{E}-4$ & $1.1 \mathrm{E}-5$ & NA & NA & NA \\
R11 & 2 & $4.1 \mathrm{E}-2$ & $2.9 \mathrm{E}-2$ & $3 \mathrm{E}-3$ & $1.9 \mathrm{E}-3$ & $1.9 \mathrm{E}-5$ \\
R12 & 1.5 & $4.2 \mathrm{E}-2$ & $3.1 \mathrm{E}-2$ & $3 \mathrm{E}-3$ & $2 \mathrm{E}-3$ & $1.9 \mathrm{E}-5$ \\
R14 & 0.41 & $8.63 \mathrm{E}-4$ & NA & NA & NA & NA \\
\hline
\end{tabular}

a Selected isotopes; RODOS allows maximum 25 isotopes.

When an optimization of the radioprotection strategy is required, countermeasures are assumed. Those countermeasures are based on the generic IAEA criteria (IAEA, 2002) and optimized with the Spanish current regulation (CSN, 2004), based on the "avoidable dose".

Since RODOS does not calculate directly the "avoidable dose" but only the "expected dose", a dose integration over elapsed time as indicated in Table 7 has been performed.

\subsection{Meteorological boundary conditions}

When dealing with the simulation of meteorological boundary conditions, a complete probabilistic analysis would need hundreds of simulations. A reasonable compromise, inspired to the safety culture, is the choice of the worst weather conditions corresponding to the larger dispersion area or the higher dose intensity to the environment.

After detailed analyses the two worst weather conditions identified are:

- a moderately intense, continuous rainfall,

- a prolonged atmospheric stability.

A constant and moderately intense rainfall is critical because the resulting isotopes deposition produces a high radiological contamination of soil and food chain. The only advantage is the faster depletion of the cloud, leading to a smaller contaminated area.

Table 7

Radioprotection strategy.

\begin{tabular}{|c|c|c|}
\hline Countermeasure & $\begin{array}{l}\text { Avoidable dose with } \\
\text { countermeasures }\end{array}$ & $\begin{array}{l}\text { Avoidable dose } \\
\text { integration time }\end{array}$ \\
\hline Sheltering & $10 \mathrm{mSv}$ & 2 days \\
\hline Evacuation & $50 \mathrm{mSv}$ & 7 days \\
\hline Stable iodine intake & $100 \mathrm{mGy}$ of radioactive iodine & $\begin{array}{l}50 \text { years for } \\
\text { adults, } \\
70 \text { years for } \\
\text { children }\end{array}$ \\
\hline Temporary transfer & $\begin{array}{l}\text { - Transfer Beginning: } \\
\text { if dose } \geq 30 \mathrm{mSv} \text {; }\end{array}$ & 30 days \\
\hline \multirow[t]{3}{*}{ Permanent transfer } & $\begin{array}{l}\text { - Transfer End:if dose }<10 \mathrm{mSv} \text {; } \\
\text { Temp.Transfer upgraded } \\
\text { to "Permanent": }\end{array}$ & 30 days \\
\hline & $\begin{array}{l}\text { - If dose }>10 \mathrm{mSv} \text {, even } \\
\text { after } 1-2 \text { years }\end{array}$ & 30 days \\
\hline & - If dose $>1 \mathrm{~Sv}$ & 70 years \\
\hline $\begin{array}{l}\text { Limitation to the } \\
\text { consumption of } \\
\text { food }\end{array}$ & $\begin{array}{l}\text { Limitation decided by the Codex } \\
\text { Alimentarius Commission and by } \\
\text { the European Commission }\end{array}$ & \\
\hline
\end{tabular}

Atmospheric stability is more critical because the cloud will travel very slowly, allowing a fairly high pollution while the absence of wet deposition will allow contaminants to stay longer in the cloud and to reach farther places than in the case of rainfall conditions.

The specific, historical, measured data corresponding to the real site considered in the analysis are obtained from Regional Environmental Protection Agency database.

Meteorological data used in the RODOS calculation are wind direction and speed, rain intensity, diffusion category and clouds covering.

\section{GenII, LR results}

Contamination maps are directly obtained from the RODOS simulations. Fig. 9 shows an example of the RODOS result for the effective dose, with the sum of all exposure pathways, in normal living conditions and integrated in 30 days for the rainy condition; Fig. 10 shows the corresponding map for the atmospheric stability conditions.

The distances that ensure a maximum dose lower than the $100 \mathrm{mSv}$ limiting dose, without countermeasures and in the worst meteorological conditions, are listed in Table 8. Design basis accident, R8, affects an area coherent with the actual legislation in both conditions.

After the frequency evaluation (Fig. 11), the maximum distance where a contamination higher than the regulation limits without any countermeasures can be expected is $19.3 \mathrm{~km}$ for the rainy conditions and $76.3 \mathrm{~km}$ for the atmospheric stability conditions.

\subsection{Countermeasures impact analysis}

Where the contamination is higher than the limiting dose established by the international regulation, protective strategies need to be applied. In this study food restrictions are not explicitly considered, while other countermeasures affecting the normal life of the population are taken into account.

A higher contamination closer to the reactor is expected under rainy conditions. The RODOS outputs allow the identification of the areas concerned in the protection strategies such as sheltering, evacuation, iodine intake for adults and children (temporary and permanent transfer are never necessary) but a comparison with actual regulation is essential to calculate the equivalent radius. Table 9 lists radii equivalent to the area in the rainy conditions.

The actual areas affected by the accident are obviously not perfect circles and therefore the calculated radii need to be mapped over areas characterized by irregular geometries and shapes. The maximum distances where countermeasures actuation is necessary in rainy condition are indicated in the same Table 9.

In atmospheric stability a wider contamination is expected as the cloud has a slow depletion and a quicker movement. The radii equivalent to the areas where countermeasures should be applied are summarized in Table 10.

There are not significant differences between the equivalent radii in rainy and stability conditions. That is reasonable because the source term is the same in both conditions, while a significant difference is evident in the values of the maximum distances of strategy protection implementation.

The radii obtained for the design basis accident are coherent with the values established by the regulation. It appears conservative because the only measure to be implemented is the food restrictions. 


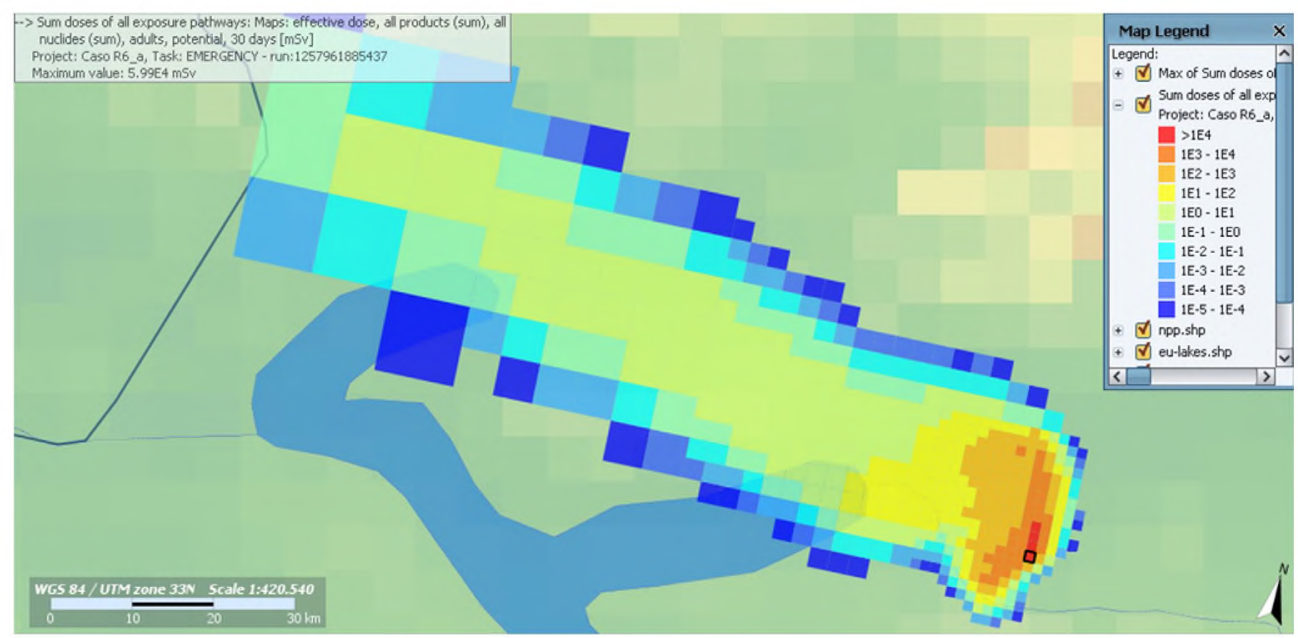

Fig. 9. Example of RODOS calculation for GenII, LR: effective dose in rainy conditions.

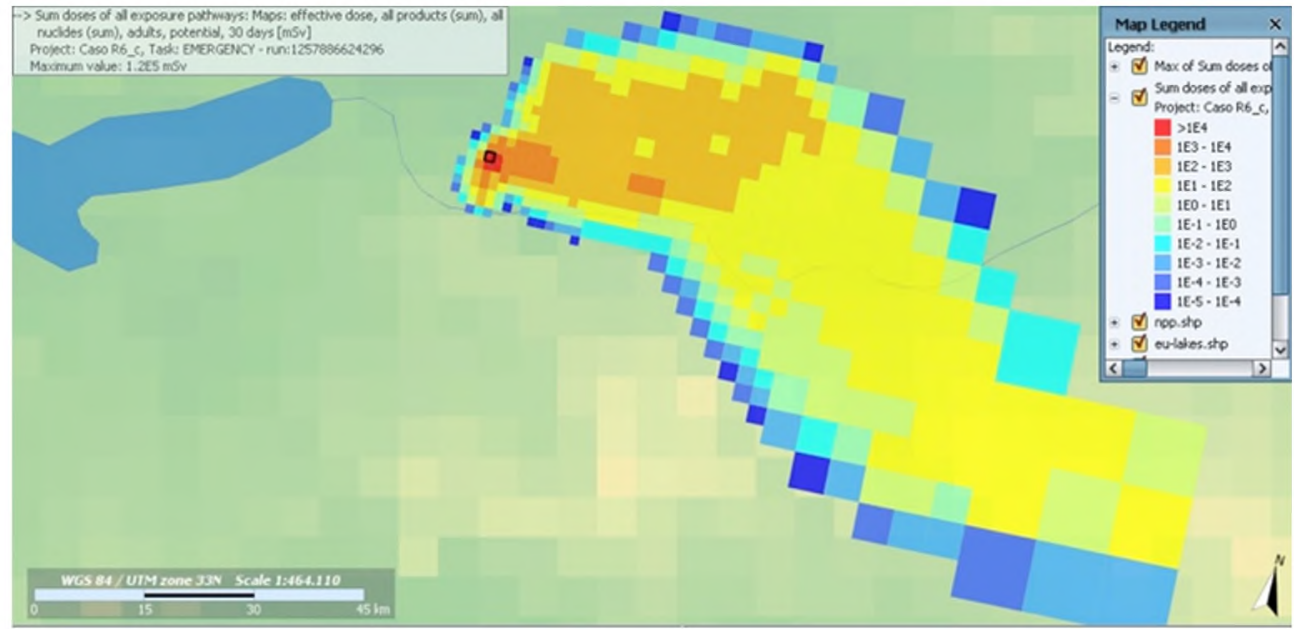

Fig. 10. Example of RODOS calculation for GenII, LR: effective dose with atmospheric stability conditions.

The areas involved in the countermeasures actuation in case of a release following severe accidents are coherent with international regulations.

\subsection{Risk informed countermeasures impacted areas}

Once the above discussed consequences are combined with the event frequencies, a risk-informed radius of influence can be calculated.

In Fig. 12 are indicated the areas of influence associated with different countermeasures.

These results can be significant if compared with the currently enforced areas of influences (e.g. Emergency Planning Zones in USA).

The calculated sheltering area of influence has a $12 \mathrm{~km}$ radius, this value is wider than the Spanish regulation requirement but within the US limits. The evacuation can concern a $16 \mathrm{~km}$ radius area, larger than the evacuation area of the EMR in Spain but similar to the USA EPZ.

The complete evacuation of the public can be finalized before the beginning of the release, thus the population does not receive any dose at the beginning of the accident. Stable iodine intake for adults would be enforced within a $9.4 \mathrm{~km}$ radius, which become a $12.4 \mathrm{~km}$ radius for iodine intake for children; these values are similar to the actual EMR area.
In stability condition the risk-informed areas of influences are represented in Fig. 13.

Sheltering equivalent radius is $13 \mathrm{~km}$, larger than in rainy condition, while the area concerned by evacuation is smaller. These results show clearly the importance of the maximum distances; the radius of the evacuation area in rainy conditions is bigger but the maximum distance is smaller than in stability conditions.

Table 8

GenII, LR: maximum distance at limiting dose $D^{*}=100 \mathrm{mSv}$.

\begin{tabular}{lll}
\hline $\begin{array}{l}\text { Release } \\
\text { category }\end{array}$ & $\begin{array}{l}\text { Rainy day distance } \\
\text { @limiting dose }[\mathrm{km}]\end{array}$ & $\begin{array}{l}\text { Atmospheric stability day } \\
\text { distance @limiting dose }[\mathrm{km}]\end{array}$ \\
\hline R1 & 18.3 & 50.8 \\
R2 & 20.9 & 97.9 \\
R3 & 16.7 & 45.0 \\
R4 & 15.8 & 45.8 \\
R5 & 16.7 & 46.5 \\
R6 & 16.1 & 47.1 \\
R7 & 15.8 & 47.1 \\
R8 & 8.7 & 0 \\
R9 & 0 & 0 \\
R10 & 19.3 & 76.3 \\
R11 & 18.5 & 60.1 \\
R12 & 18.6 & 64.9 \\
\hline
\end{tabular}




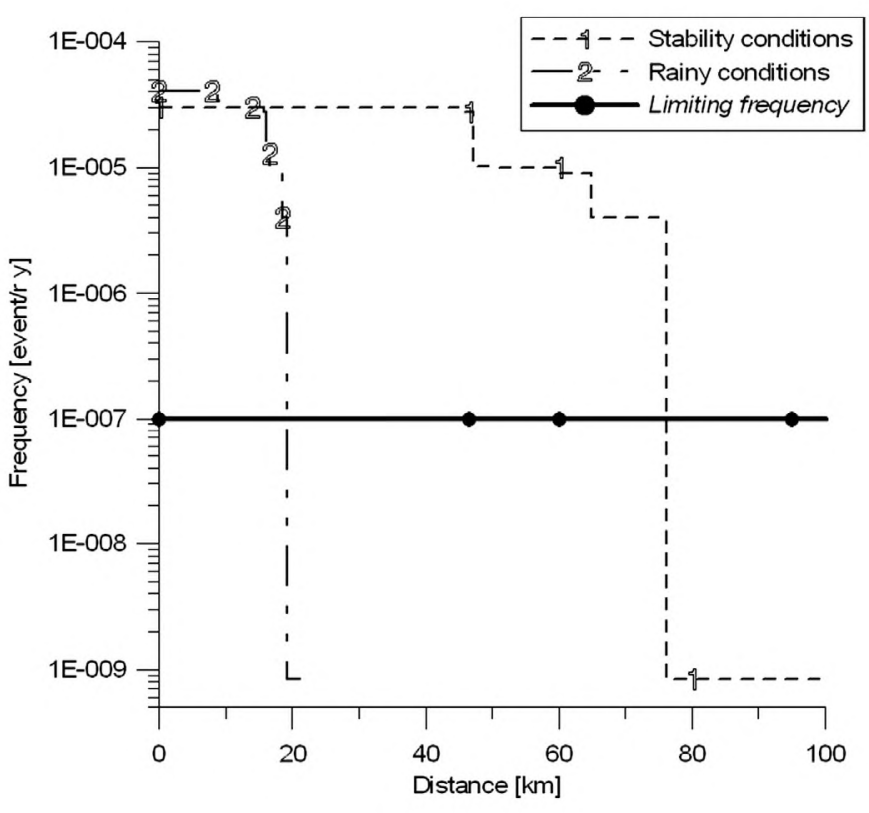

Fig. 11. GenII, LR results.

Stable iodine intake affects the population in an equivalent radius of $12.5 \mathrm{~km}$ for adults and $13 \mathrm{~km}$ for children: these radii are larger than in rainy conditions, but it is possible to ensure the intake before the release or the cloud arrival.

The study analysed very low frequency accidents with a high dose. The results in critical meteorological conditions show that the actual EMR requirements for the design basis accident could protect the public from the earlier effects of severe accidents.

\section{GenIII+, SMR results}

IRIS accidents resulting in releases beyond the regulation limits have a lower frequency than the limiting frequency value accepted for this work; other accidents produce a dose lower than limits. The area affected by a dose higher than $100 \mathrm{mSv}$ in thirty days is zero. Table 11 shows the maximum dose values, measured close to the reactor's boundary: they are not very high, except for some accidents.

The preliminary evaluation based on $100 \mathrm{mSv}$ in thirty days is conservative, with the assumption that the population lives in open air and eats all the products of the contaminated area. The EMR area is still negligible in these conditions. A second, more limiting case, consistent with the ALARA principle, is evaluated with a $10 \mathrm{mSv}$

Table $\mathrm{g}$

GenII, LR: equivalent radius of the EMR area, rainy case (in brackets: Maximum value).

\begin{tabular}{|c|c|c|c|c|c|c|c|c|}
\hline \multirow{2}{*}{$\begin{array}{l}\text { Rel cat } \\
\text { R1 }\end{array}$} & \multicolumn{2}{|c|}{$\begin{array}{l}\text { Sheltering } \\
{[\mathrm{km}]}\end{array}$} & \multicolumn{2}{|c|}{$\begin{array}{l}\text { Evacuation } \\
{[\mathrm{km}]}\end{array}$} & \multicolumn{2}{|c|}{$\begin{array}{l}\text { Iodine-adults } \\
{[\mathrm{km}]}\end{array}$} & \multicolumn{2}{|c|}{$\begin{array}{l}\text { lodine- } \\
\text { children [km] }\end{array}$} \\
\hline & 11.8 & $(32.2)$ & 14.3 & $(32.2)$ & 6.1 & $(11)$ & 9.4 & $(31.8)$ \\
\hline $\mathrm{R} 2$ & 14.1 & (32.3) & 15.9 & (32.3) & 13.9 & (32.3) & 14.1 & $(32.2)$ \\
\hline R3 & 5.8 & (11) & 11.8 & (32.2) & 5.4 & $(10.6)$ & 5.8 & $(11)$ \\
\hline R4 & 5.2 & $(9.9)$ & 13.9 & (32.2) & 5.3 & $(9.9)$ & 5.7 & $(11.2)$ \\
\hline R5 & 9.4 & (31.9) & 13.9 & (32.3) & 5.8 & (11) & 6.1 & $(11)$ \\
\hline R6 & 5.2 & $(9.9)$ & 13.9 & (32) & 5.7 & (11) & 9.0 & $(30.3)$ \\
\hline R7 & 5.2 & (10) & 13.9 & (32) & 5.2 & $(9.9)$ & 6.1 & $(10.8)$ \\
\hline R8 & 0 & $(0)$ & 0 & $(0)$ & 0 & $(0)$ & 0 & $(0)$ \\
\hline R9 & 0 & $(0)$ & 0 & $(0)$ & 0 & $(0)$ & 0 & $(0)$ \\
\hline R10 & 12.0 & (32.3) & 15.9 & $(32.0)$ & 9.4 & (32) & 12.4 & $(32.3)$ \\
\hline R11 & 11.8 & (32.2) & 15.8 & (32.2) & 5.8 & (11.1) & 9.4 & $(32.6)$ \\
\hline R12 & 11.8 & (32.3) & 15.8 & (32.3) & 5.8 & (11) & 9.4 & (32.2) \\
\hline
\end{tabular}

Table 10

GenII, LR: equivalent radius of the EMR area, stability case (in brackets: maximum value).

\begin{tabular}{|c|c|c|c|c|c|c|c|c|}
\hline \multirow{2}{*}{$\begin{array}{l}\text { Rel cat } \\
\text { R1 }\end{array}$} & \multicolumn{2}{|c|}{$\begin{array}{l}\text { Sheltering } \\
{[\mathrm{km}]}\end{array}$} & \multicolumn{2}{|c|}{$\begin{array}{l}\text { Evacuation } \\
{[\mathrm{km}]}\end{array}$} & \multicolumn{2}{|c|}{$\begin{array}{l}\text { Iodine-adults } \\
{[\mathrm{km}]}\end{array}$} & \multicolumn{2}{|c|}{$\begin{array}{l}\text { Iodine- } \\
\text { children }[\mathrm{km}]\end{array}$} \\
\hline & 11.7 & (43.3) & 12.5 & (44.8) & 4.9 & (5.5) & 5.2 & (10) \\
\hline R2 & 13.8 & (51.9) & 14.5 & (55.5) & 13.1 & (47) & 13.7 & (51.8) \\
\hline R3 & 4.9 & (5.5) & 4.8 & (5.5) & 4.9 & (5.5) & 4.9 & $(5.5)$ \\
\hline R4 & 4.9 & $(5.5)$ & 4.8 & $(5.5)$ & 5.7 & (11) & 11.6 & (32.5) \\
\hline R5 & 4.9 & (5.5) & 5.2 & $(10)$ & 4.9 & (5.5) & 4.9 & $(5.5)$ \\
\hline R6 & 5.2 & (9.9) & 5.7 & (11) & 11.5 & (32.4) & 13.6 & (32.7) \\
\hline R7 & 4.9 & (5.5) & 5.7 & (11) & 5.7 & (11) & 11.6 & $(32.7)$ \\
\hline R8 & 0 & (0) & 0 & (0) & 0 & (0) & 0 & (0) \\
\hline R9 & 0 & $(0)$ & 0 & $(0)$ & 0 & $(0)$ & 0 & (0) \\
\hline R10 & 13 & (47.1) & 13.6 & (51.8) & 12.4 & (45.5) & 13.3 & $(52.9)$ \\
\hline R11 & 12.7 & (47) & 13.0 & (47.1) & 12 & (43.2) & 12.4 & $(45.8)$ \\
\hline R12 & 12.8 & (47.1) & 13.3 & (51.9) & 12 & (43.3) & 12.6 & $(45.7)$ \\
\hline
\end{tabular}

limiting dose, calculated in the same conservative conditions. This value is also lower than the minimum limit set by ICRP.

In rainy conditions only two accidents (R14 and R3) with a significant frequency produce a maximum dose higher than $10 \mathrm{mSv}$. Table 12 shows the distances to ensure a dose lower than $10 \mathrm{mSv}$ without countermeasures. In atmospheric stability conditions, the distance values are larger.

Distances for R7 and R13 release scenarios are considered infinite with a conservative assumption. Beyond the $10 \mathrm{~km}$ distance there are no changes in the frequency because it is lower than the accepted limit. The maximum distance where it is possible to reach a dose higher than $10 \mathrm{mSv}$ (Fig. 14) in rainy conditions is $932 \mathrm{~m}$, while in stability conditions the value rises to $1735 \mathrm{~m}$ (R14 case, corresponding to the fuel handling accident, which conservatively has a relative high frequency with significant consequences). Such conservative value of $1735 \mathrm{~m}$ is still very small in comparison with the actual EMR area.

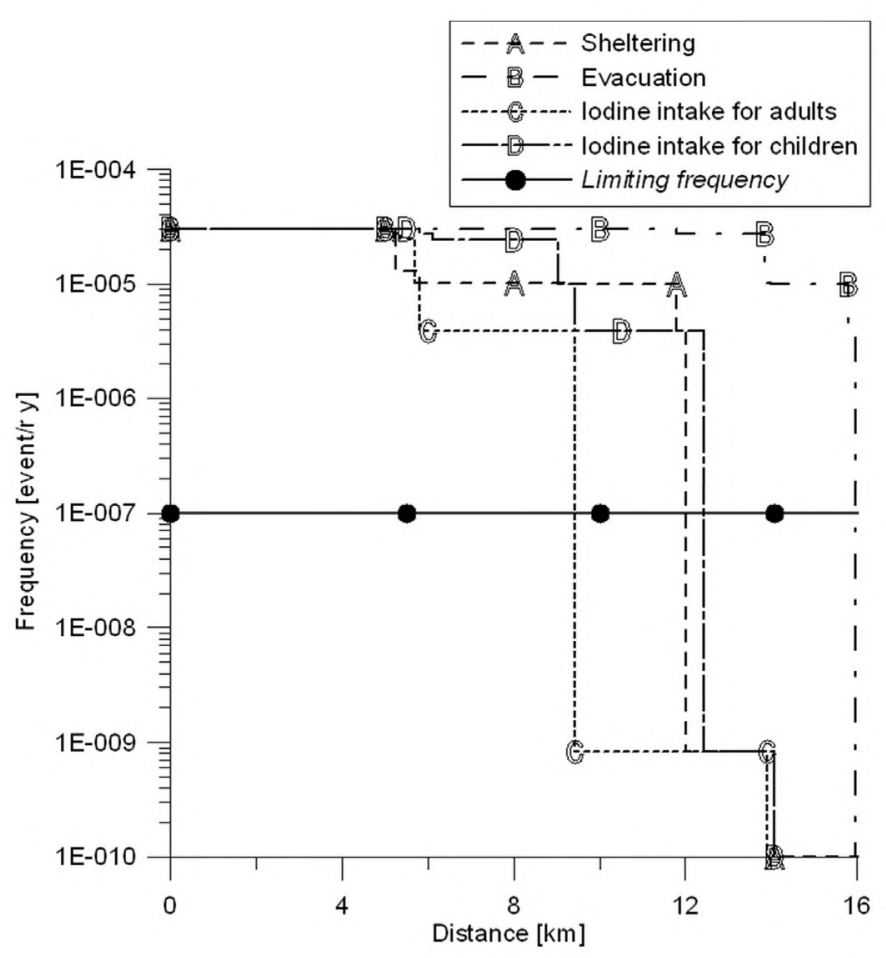

Fig. 12. GenII, LR - countermeasures in rainy conditions, for equivalent radius EMR area. 


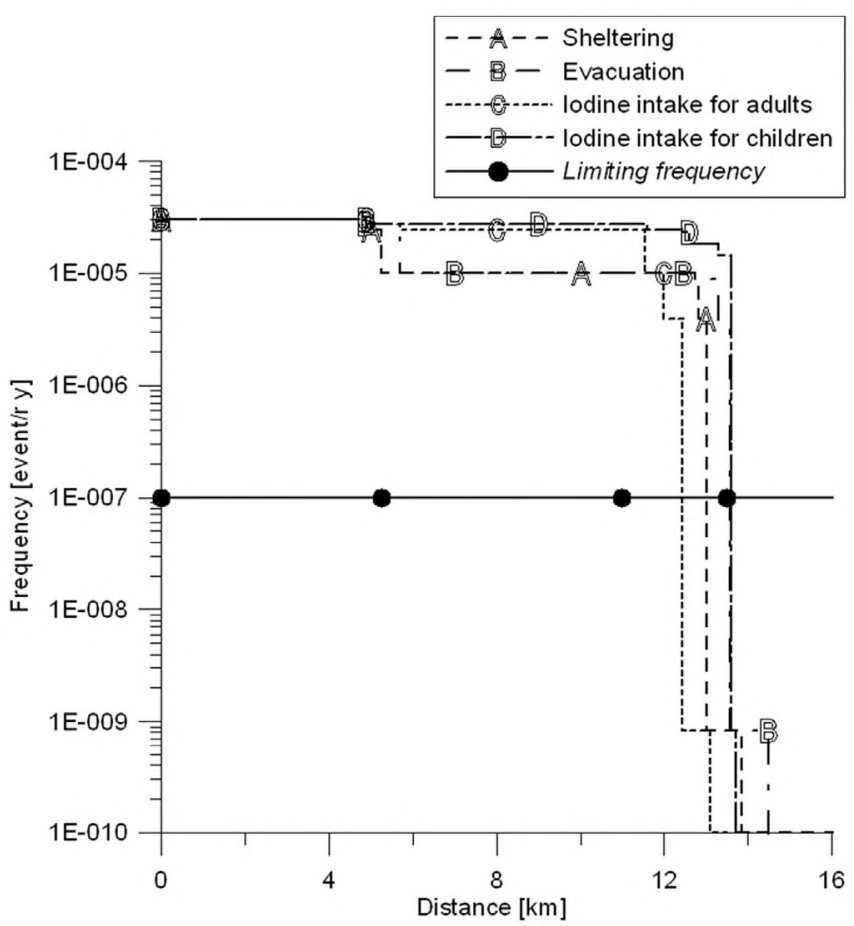

Fig. 13. GenII, LR - countermeasures in stability conditions, for equivalent radius EMR area.

The results herein obtained with RODOS are consistent with the initial calculation performed with RADTRAD. In a previous study, corresponding to uniform dispersion without meteorological changes, the calculated area was $1800 \mathrm{~m}$.

It has to be pointed out that the results of the analysis for a GenII, LR and a GenIII+, SMR presented in this paper represent only a test case for the proposed methodology. For the sake of simplicity, uncertainties have not been evaluated and considered in the analysis. They are indeed a very important step in any deterministic and probabilistic approach. In principle, uncertainty evaluation should have an impact on the final results, but it not impairs the methodology: uncertainties would simply modify Fig. 4 into Fig. 15. In this case, the limiting frequency line does not identify a specific point, hence a fixed distance, for the EMR area but a range instead.

\section{Conclusions}

The results obtained in the paper, referring to a risk-informed calculation of the size of the EMR area where the radiological

Table 11

GenIII+, SMR: Maximum doses for release categories.

\begin{tabular}{lll}
\hline Release category & $\begin{array}{l}\text { Rainy day maximum } \\
\text { dose }[\mathrm{mSv}]\end{array}$ & $\begin{array}{l}\text { Atmospheric stability day } \\
\text { maximum dose }[\mathrm{mSv}]\end{array}$ \\
\hline R1 & 0.3 & 0.7 \\
R2 & 1.5 & 9 \\
R3 & 12.7 & 31.6 \\
R4 & 0.4 & 1.1 \\
R5 & 0.5 & 1.1 \\
R6 & 0.6 & 1.4 \\
R7 & - & - \\
R8 & 0.06 & 0.15 \\
R9 & 0.3 & 0.7 \\
R10 & 3.4 & 11 \\
R11 & 520 & 952.3 \\
R12 & 1087 & 971.1 \\
R13 & - & - \\
R14 & 41.7 & 58.6 \\
\hline
\end{tabular}

Table 12

GenIII+, SMR: Distance at limiting dose $D^{*}=10 \mathrm{mSv}$.

\begin{tabular}{lll}
\hline Release Category & $\begin{array}{l}\text { Rainy day distance } \\
\text { @ limiting dose }[\mathrm{m}]\end{array}$ & $\begin{array}{l}\text { Atmospheric stability day } \\
\text { distance @ limiting dose [m] }\end{array}$ \\
\hline R1 & 0 & 0 \\
R2 & 0 & 0 \\
R3 & 294 & 1013 \\
R4 & 0 & 0 \\
R5 & 0 & 0 \\
R6 & 0 & 0 \\
R7 & $\infty$ & $\infty$ \\
R8 & 0 & 0 \\
R9 & 0 & 0 \\
R10 & 0 & 0 \\
R11 & 10,551 & 43,647 \\
R12 & 9246 & 43,635 \\
R13 & $\infty$ & $\infty$ \\
R14 & 932 & 1735 \\
\hline
\end{tabular}

protection countermeasures for the population should be applied, show a sensible difference between a GenII, "classical" safety level reactor and a GenIII+ reactor with "enhanced" safety, confirming the basis for a discussion, devoted to identify suitable procedures for revising and updating the EMR area definition approach.

The GenII, LR and GenIII+, SMR DBAs do not induce any countermeasure implementation, while for the BDBAs there is a significant difference between the behaviour of the reactors belonging to the two generations. Severe accidents have always a major impact and cause an extensive contamination, but in the accident scenarios for the GenIII+ reactor a lower limiting dose $(10 \mathrm{mSv}$, instead of $100 \mathrm{mSv}$ adopted for the GenII reactor) is reached in a very limited area and at a low frequency of occurrence value $\left(10^{-7}\right.$ event/r y), the latter corresponding to a limiting frequency a regulator could reasonably accept.

That means the GenIII + reactor could avoid the implementation of countermeasures also for severe accident scenarios, considering that at the very conservative limiting dose of $10 \mathrm{mSv}$ an EMR area can be established in less than $2 \mathrm{~km}$ radius.

The risk-informed results for the GenII, LR substantially confirm the soundness of the current regulation for the level of safety of present NPPs: countermeasure application areas, calculated by means of a risk-informed approach, are coherent e.g. with the US

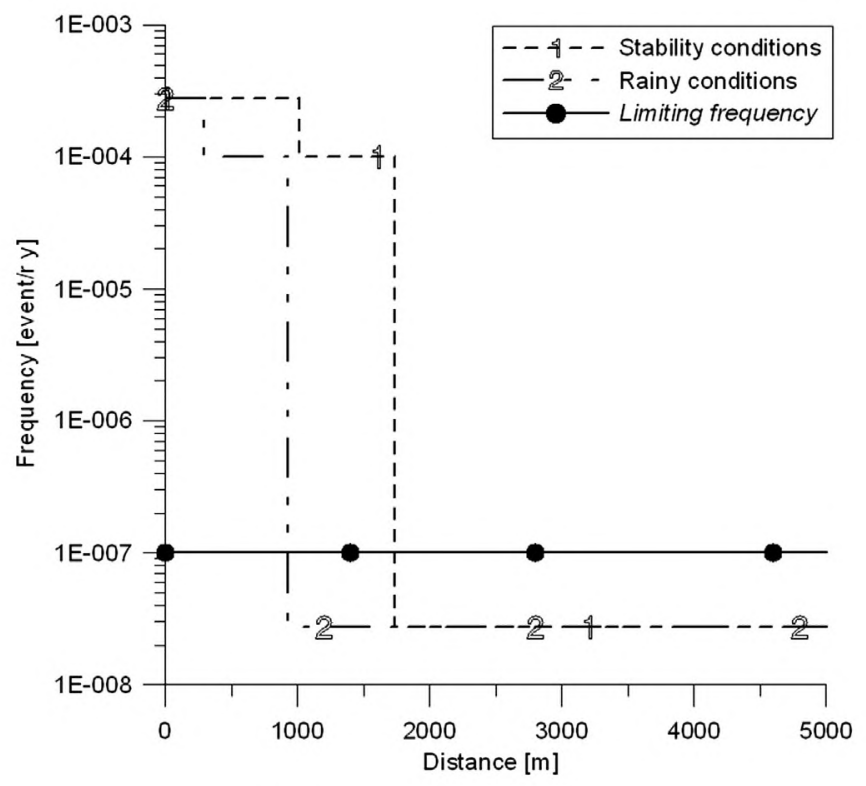

Fig. 14. GenIII+, SMR (IRIS) results. 


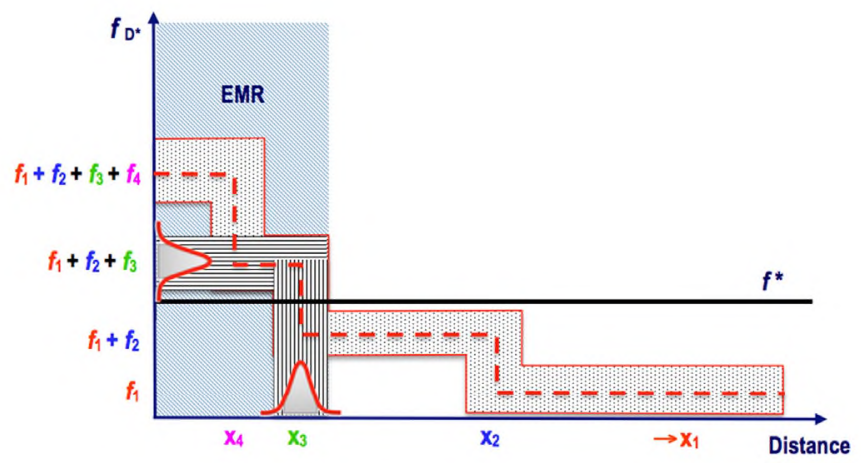

Fig. 15. EMR area definition with uncertainties evaluated both on deterministic and probabilistic analysis.

regulation. The actual EMR areas could protect against accident scenarios not considered at that time in the studies, when the current regulation was developed. The actual application of countermeasures does not involve all the area but only some sectors, according to meteorological conditions, and the awareness of the real impact of severe accidents can help a better organization of the emergency procedures.

The sensible and methodologically justified reduction of the EMR areas, achievable with the risk-informed approach and for reactors with enhanced or ultimate safety features, as it is likely the case of GenIII+ reactors, could result in an increase in the public acceptance of the nuclear power plants.

\section{Acknowledgements}

The work described in this paper has been developed under a collaboration between the Politecnico di Milano and the Universidad Politécnica de Madrid. The methodology was originally developed by Andrea Maioli during his PhD thesis: he is gratefully acknowledged by the Authors.

\section{Acronyms}

BDBA Beyond Design Basis Accident

DBA Design Basis Accident

DOE Department of Energy

EA Exclusion Area

EMR Emergency Management Requirement

EPA Environment Protection Agency

GIF Generation IV International Forum

IEP Ingestion Exposure Pathway

INPRO International Project on Innovative Nuclear Reactors and Fuel Cycles

IRIS International Reactor Innovative and Secure

LR Large size Reactor

LPZ Low Population Zone

LWR Light Water Reactor

NERI Nuclear Energy Research Initiative

NPP Nuclear Power Plant

NRC Nuclear Regulatory Commission

PAGs Protective Actions Guide

PEP Plume Exposure Pathway

PWR Pressurized Water Reactor

SMR Small-Medium size Modular Reactor

\section{References}

ANS, 2011. Nuclear Safety Criteria and Safety Design Process for Modular HeliumCooled Reactor Plants. ANSI/ANS-53.1-2011. American Nuclear Society, 555 North Kensington Avenue, La Grange Park, Illinois 60526 USA.

Boarin, S., Locatelli, G., Mancini, M., Ricotti, M.E., 2012. Financial case studies on small and medium-size modular reactors. Nucl. Technol. 178, 218-232.

CSN, 2004. Real Decreto 1546/2004, de 25 de junio, por el que se aprueba el Plan Básico de Emergencia Nuclear. Consejo Seguridad Nuclear, Boletín Oficial del Estado, Spain, 14 julio de 2004.

Ehrhardt, J., 1997. The RODOS system: decision support for off-site emergency management in Europe. Radiat. Prot. Dosim. $73(1-4), 35-40$.

Ehrhardt, J., Päsler-Sauer, J., Schüle, O., Benz, G., Rafat, M., Richter, J., 1993. Development of RODOS, a comprehensive decision support system for nuclear emergencies in Europe - an overview. Radiat. Prot. Dosim. 50 (2-4), 195-203.

EPA, 1975. Manual of Protective Action Guides and Protective Actions for Nuclear Incidents. EPA-520/1-75-001. US Environmental Protection Agency.

EPRI, 1999. Technical Aspects of ALWR Emergency Planning. TR-113509, Palo Alto, CA, USA.

EUR, 2002. European Utility Requirements for LWR Nuclear Power Plants, Rev. C. http://www.europeanutilityrequirements.org/eur.htm.

Gauntt, R.O., et al., 2005. MELCOR Computer Code Manuals -. NUREG/CR-6119, Vol. 2 Rev 3, SAND 2005-5713. In: Reference Manuals, Version 1.8.6, vol. 2. Sandia National Laboratories, Albuquerque, New Mexico.

GIF, 2002. A Technology Roadmap for Generation IV Nuclear Energy Systems. GIF002-00. US DOE, Washington D.C., USA.

Humphreys, S.L., Heames, T.J., Miller, L.A., Monroe, D.K., 1998. RADTRAD: a Simplified Model for RADionuclide Transport and Removal and Dose Estimation. NUREG/CR-6604 SAND98-0272. http:/www.osti.gov/bridge/product. biblio.jsp?osti_id $=604405$.

IAEA, 1999. Basic Safety Principles for Nuclear Power Plants. 75-INSAG-3 Rev. 1. INSAG series n.12. Vienna, Austria.

IAEA, 2002. Preparedness and Response for a Nuclear or Radiological Emergency: Safety Guide. Safety Standards Series no. GS-R-2. Vienna, Austria.

IAEA, 2003. Guidance for the Evaluation of Innovative Nuclear Reactors and Fue Cycles, Report of Phase 1A of the International Project on Innovative Nuclear Reactors and Fuel Cycles (INPRO). IAEA-TECDOC-1362, Vienna.

IAEA, 2005. Chernobyl's Legacy: Health, Environmental and Socio-economic Impacts and Recommendations to the Governments to Belarus, the Russian Federation and Ukraine, second revised version. The Chernobyl Forum, Vienna, Austria. 2003-2005.

IAEA, 2007. Status of Small Reactor Designs without On-site Refuelling. IAEA-TECDOC-1536, Vienna, Austria.

IAEA, 2010. Fundamental Safety Principles (Safety Standards Series No. SF-1). Vienna, Austria.

IAEA, 2010b. Small Reactors without On-site Refuelling: Neutronic Characteristics, Emergency Planning and Development Scenarios. IAEA-TECDOC-1652, Vienna, Austria.

ICRP, 1999. Protection of the Public in Situations of Prolonged Radiation Exposure, vol. 82. ICRP Publication. Ann. ICRP $29(1-2)$.

Ingersoll, D.T., 2009. Deliberately small reactors and the second nuclear era. Prog. Nucl. Energy 51 (4-5), 589-603.

Lee, Y.W., Kang, C.S., Moon, J.H., 2004. Reduction of EPZ area for APR1400 and its public acceptance. Prog. Nucl. Energy 44 (2), 75-84.

MAAP, 1994. MAAP4: Modular Accident Analysis Program for LWR Plants, Code Manual, vols. 1-4. Fauske \& Associates Inc., Burr Ridge, Ill, USA.

NEI, 2002. A Risk-informed, Performance-based Regulatory Framework for Power Reactors. NEI02-02, Washington D.C., USA.

NRC, 1981. NRC Standard Review Plan. NUREG-0800. US Nuclear Regulatory Commission.

NRC, 1990. Special Committee Review of the Nuclear Regulatory Commission's Severe Accident Risks Report (NUREG 1150). NUREG-1420. US Nuclear Regulatory Commission.

NRC, 1991. Severe Accident Risks: An Assessment for Five U.S. Nuclear Power Plants. NUREG-1150. US Nuclear Regulatory Commission.

NRC, 2003. Reactor Site Criteria, 10-CFR-100. US Nuclear Regulatory Commission.

NRC, 2011. Recommendations for Enhancing Reactor Safety in the 21st Century. The Near-term Task Force Review of Insights from the Fukushima Dai-ichi Accident. US Nuclear Regulatory Commission. http://pbadupws.nrc.gov/docs/ML1118/ ML111861807.pdf.

Päsler-Sauer, J., 2007. Model Description of the Early Countermeasures Module EmerSim. RODOS PV 6.0. Final Report RODOS(RA3)-TN(04)-03, FZK.

Petrovic, B., Ricotti, M.E., Monti, S., Cavlina, N., Ninokata, H., 2012. Pioneering role of IRIS in the resurgence of small modular reactors. Nucl. Technol. 178, 126-152.

RODOS, 2008. Realtime Online Decision Support System for Nuclear Emergency Management. Homepage: http://www.rodos.fzk.de/rodos.html.

Rojas-Palma, C., Madsen, H., Gering, F., Puch, R., Turcanu, C., Astrup, P., Müller, H. Richter, K. Zheleznyak, M. Treebushny, D., Kolomeev, M., Kamaev, D., Wynn, H. 2003. Data assimilation in the decision support system RODOS. Radiat. Prot. Dosim. 104 (1), 31-44.

Thompson Jr., H.L., 1997. Results of Evaluation of Emergency Planning for Evolutionary and Advanced Reactors. SECY-97-020. US Nuclear Regulatory Commission. 